\section{Dança e ação social: implicação do lugar da arte contemporânea ${ }^{1}$}

\author{
Dance and social action: implication of \\ the place of contemporary art
}

Marina Souza Lobo GUZZO²

Mary Jane Paris SPINK ${ }^{3}$

\section{RESUMO}

Este artigo tem como foco o espetáculo ENCARNADO da coreógrafa brasileira Lia Rodrigues. O trabalho foi criado a partir da mudança da Lia Rodrigues Companhia de Danças para a Favela da Maré, no Rio de Janeiro. "Residir" e construir seu trabalho na favela foram fatores determinantes e fundamentais para as características da obra e indicam um comprometimento com o lugar que extrapola um determinado trabalho ou projeto artístico. O compromisso passa a ser com as conexões e com a identidade que aquele lugar imprime na vida da coreógrafa, dos bailarinos e de seus trabalhos.

Palavras-chave: Dança. Ação social. Favela da Maré.

\section{ABSTRACT}

This article focuses on the spectacle ENCARNADO of Brazilian choreographer Lia Rodrigues. The work was created after the change of Lia Rodrigues's Dances Company to the Favela da Mare in Rio de Janeiro. "To live" and build up her work in the slums was crucial and fundamental to the project's characteristics, providing a partnership with the community. This action indicates a commitment to the place that goes beyond a particular work or artistic project. The compromise becomes closer with the connections and the identity that place prints in the choreographer's and the dancer's lives and their work.

Keywords: Dance. Social action. Favela da Maré.

\author{
1. $O$ artigo é inédito e foi \\ baseado na tese da autora, \\ intitulada: Dança em Ação: \\ políticas de resistência no \\ Encarnado de Lia Rodrigues, \\ defendida em 2009, na \\ Pontifícia Universidade Católica \\ de São Paulo, com financia- \\ mento da CAPES e do CNPq. \\ 2. Doutora em Psicologia \\ pela Pontifícia Universidade \\ Católica de São Paulo. Docente \\ da Universidade Federal de São \\ Paulo. ORCID: http://orcid.org/ \\ 0000-0002-9978-4014 \\ E-mail: \\ marinaguzzo2@gmail.com
}

3. Doutora em Psicologia Social pela University of London. Professora Titular na Pontifícia Universidade Católica de São Paulo. ORCID: http://orcid.org/ 0000-0003-1672-505X E-mail:mjspink@pucsp.br

Submetido em: 12/01/2016, aceito em: 04/06/2016. 
O espetáculo ENCARNADO, inspirado em Diante da dor dos outros, obra da escritora americana Susan Sontag, teve sua estreia em 2005, no Centre National de la Danse - CND - em Pantin, França. Em 2007, estreou em São Paulo, no espaço do $9^{\circ}$ andar do SESC, Unidade Avenida Paulista, após ter sido apresentado por mais de 100 vezes em 11 países (KATZ, 2007). Sua criação foi feita a partir da mudança da Lia Rodrigues Companhia de Danças (2013) para a Favela da Maré, no Rio de Janeiro.

A decisão de mudar sua residência artística da zona sul para a Maré aconteceu por convite do Centro de Estudos e Ações Solidárias da Maré (CEASM), uma organização não governamental (ONG) que desenvolve trabalhos há oito anos nessa comunidade ${ }^{4}$. Criada em 15 de agosto de 1997, o CEASM atua no conjunto de comunidades populares da Maré, área da cidade do Rio de Janeiro que reúne cerca de 130 mil moradores (CENSO 2000). O CEASM foi fundado por moradores e ex-moradores locais que dirigem o espaço e, em sua grande maioria, conseguiram chegar à universidade. Os projetos desenvolvidos visam superar as condições de pobreza e exclusão existentes na Maré, apontado como o terceiro bairro de pior Índice de Desenvolvimento Humano da cidade.

Na passagem de 2007 para 2008, houve uma divisão entre pessoas que trabalhavam no CEASM, por questões e interesses diversos. A companhia de Lia Rodrigues mudou-se para outra instituição, a Redes de Desenvolvimento da Maré5 (REDES), com a qual a artista manteve o vínculo para ações da companhia na região, com 16 comunidades (CENSO, 2000). Esse encontro possibilitou uma série de ações na área das artes, que coincidiu com o projeto da companhia, fundada há 26 anos. Desde 1990, Lia Rodrigues desenvolve seu trabalho com o objetivo de estimular a reflexão, proporcionar espaços de debate, sensibilizar as pessoas para as questões da arte contemporânea, gerar encontros intelectuais e afetivos, além de apoiar e investir na formação e na informação de novas plateias.

Uma das consequências da parceria entre a REDES e a Lia Rodrigues Companhia de Danças foi a conquista coletiva de um espaço físico que abriga, além da residência desse grupo, um projeto de integração de diferentes práticas artísticas, que pretende ser uma referência para os moradores da Maré e de outros bairros da cidade do Rio de Janeiro. O espaço, um galpão de 700 metros quadrados localizado na rua Bittencourt Sampaio, 195, em Nova Holanda, esteve fechado por mais de 15 anos. Apesar da precariedade de seu estado, sua localização estratégica, assim como sua amplitude fazem dele um local privilegiado
4 O CEASM fundou a Casa de Cultura da Maré, após ter recebido, em 2003, a doação de um antigo galpão que servia de oficinas para navio. Foi nesse galpão que Lia Rodrigues começou a desenvolver seus trabalhos na Maré (CEASM, 2016).

5 A Redes de

Desenvolvimento da Maré (REDES) foi criada em março de 2007 e legalizada em julho do mesmo ano. Sua criação materializou um longo processo de ações, pesquisas e reflexões desenvolvidas nas comunidades da Maré. Sua missão é promover a construção de uma rede de desenvolvimento sustentável através de projetos que articulem diferentes atores sociais comprometidos com a transformação estrutural da Maré e produzam conhecimentos e ações relativas aos espaços populares que interfiram na lógica de organização da cidade e contribuam para superar todas as formas de violência (REDES DA MARÉ, 2016). 
para a criação artística, para a difusão de obras e, sobretudo, para a troca rica e criativa entre os artistas e a população do Rio.

A proposta da coreógrafa não era realizar "trabalho social" no espaço, mas desenvolver o seu próprio trabalho artístico de criação. Por conta disso, emergem outras perguntas acerca da comunicação e da produção de sentidos da dança, que correlacionam seu espaço e tempo. Por se tratar de uma linguagem artística impermanente e efêmera, o lugar onde ela acontece carrega uma responsabilidade importante para a delineação do espetáculo como um produto, ou ainda, como um processo criativo.

Lia Rodrigues afirma que sua vontade era experimentar alguma coisa nova; colocar-se em risco, colocar em risco sua dança, procurar sentido em um lugar que inicialmente se fazia tão distante e diferente de sua realidade. "E todas aquelas pessoas que vivem nessas condições? Como posso me aproximar delas? Como posso fazer arte com/para elas? Será que funciona?" (RODRIGUES apud GUZZO, 2008).

Ao deslocar sua companhia de dança do centro de uma das maiores cidades do Brasil, o Rio de Janeiro, para a maior favela do país, Rodrigues aborda, em sua obra, questões habitacionais, sociais e culturais muito pertinentes sobre a vida nas cidades hoje. As favelas estão cada vez mais presentes, "[...] de olhos acesos, barulhando, produzindo riquezas, criando recursos para driblar as consequências dos desmandos de um país injusto" (LINS apud SILVA \& BARBOSA, 2005, p.15), e são um local onde a violência e a falta de acesso aos direitos básicos de qualquer ser humano são abundantes.

Para grande parte da população, a favela faz parte de outra cidade, onde imperam outras leis e a violência caracteriza qualquer forma de relação de poder. Outra imagem, também pré-concebida desde os tempos dos cortiços cariocas, é a da favela como um lugar sujo, ambiente de vagabundos e baderneiros, sítio propagador de doenças e de pestes. A favela como um "problema" é uma noção muito presente no senso comum, assim como a ideia de que é um espaço de resistência ao mundo urbano. Silva \& Barbosa (2005) explicitam que a favela faz parte da cidade, da sua vida e da sua história, com uma realidade plural e diversa. É um lugar que deve se tornar visível - seu cotidiano, suas ruas, suas casas - para que seja superada a desigualdade e as injustiças que ali ocorrem.

Ao relacionar a dança com o lugar, o espetáculo ENCARNADO (2005) assume um sentido crítico e político para a crítica especializada e para o público, pois, além de seu conteúdo, decorrente das escolhas temáticas e estéticas, o lugar passa a ser característica importante para sua apreciação e para sua descrição. Nos textos sobre o ENCARNADO, publicados 
em diferentes mídias, o fato de a criação ter sido realizada na Favela da Maré é sempre destacado. Seja no discurso da crítica especializada, seja no texto escrito pela própria Lia Rodrigues (2008) para descrever o processo criativo do espetáculo:

O corpo é um estado e, dependendo de onde ele está, esse estado muda. Daía decisão de propor uma residência da companhia na Favela da Maré, junto ao CEASM (Centro de Estudos e Ações Solidárias da Maré), uma organização não-governamental que desenvolve há oito anos um importante trabalho sociopedagógico nessa comunidade. A Maré é um conjunto de comunidades populares na cidade do Rio de Janeiro que reúne cerca de $132 \mathrm{mil}$ moradores. É importante entender que na cidade do Rio de Janeiro a favela não é periférica, ela não cerca a cidade. Ela está dentro da cidade, é central, determinando a convivência de universos sociais muito distintos. E, apesar desse estreito convívio, é grande o isolamento desses mundos (RODRIGUES, 2008).

Sobretudo nas críticas e reportagens internacionais, nos quais a favela constitui-se como um lugar ainda mais mítico e distante, "a tragédia brasileira" é destacada quando se trata do ENCARNADO, como nos exemplos de duas críticas que seguem abaixo:

Rodrigues vê seu trabalho como um "manifesto", que é presenteado à plateia com os horrores da vida (e da morte) numa favela brasileira, e ela se mostra de maneira a romper deliberadamente com o conforto de sua audiência. [...] As imagens que ela nos mostra são, ao mesmo tempo, desprazerosas e charmosas - e em sua beleza repugnante encontramos uma fascinação, que nos desenha as tragédias da realidade brasileira (PALMER, 2007, tradução das autoras). ${ }^{6}$

Quatro anos atrás, Rodrigues se mudou com sua companhia para fora da cidade do Rio de Janeiro para a Favela da Maré, uma das maiores e mais pobres favelas do Rio de Janeiro, com a intenção de forçar a comunidade artística da cidade a sair de seu conforto (INNES, 2007, tradução das autoras). ${ }^{7}$

Os sentidos produzidos pelo lugar são importantes para o entendimento da obra de dança contemporânea: onde se ensaia, como se relaciona com a comunidade, onde se escolhe apresentar ou estrear um espetáculo. O fato da Lia Rodrigues Companhia de Danças ter-se mudado para a Favela da Maré, influenciou na dança que produziam. O lugar gerou novas conexões para a criação e para o movimento. Como relata um bailarino da companhia ao referir-se sobre o fato de estarem nesse novo ambiente:

Estar na favela muda tudo...(...) você não pensa quando está em Copacabana. Você só está e pronto. Na Maré você fica o tempo todo pensando nisso; você fica reparando em tudo (...) tem muito barulho, os caras armados, parece um exército (GUZZO, 2009).
6. No original: "Rodrigues sees her work as "a manifesto", a means by which to present her audience with the horrors of life (and death) in a Brazilian favela and she sets out to deliberately disrupt the comfort of her audience. [...] The images she shows us are both gross and beguiling - and in their repugnant beauty we find a fascination, which draws us in to these tragedies of Brazilian reality.

7. "Four years ago, Rodrigues moved her company out of the city to the Favela de Maré, one of the largest, poorest shantytowns of Rio de Janeiro, intending to force the city's artistic community out of its complacency". 
O lugar também propõe outras conexões para a rede do ENCARNADO. Mais do que identidade e experiências (TUAN, 1983), os lugares são agregados de relações que integram uma rede global e podem ter grandes variações de tamanho, indo desde o pequeno lugar conhecido pela experiência direta, até o estado-nação, que "[...] pode ser transformada em lugar - uma localização de lealdade apaixonada - através do meio simbólico da arte, da educação e da política" (TUAN, 1983, p.149). Nesse sentido, o deslocamento da companhia e a criação de um espetáculo em um lugar "diferente" proporciona um olhar para o mundo, para a situação social e econômica do país (ou pelo menos da cidade do Rio de Janeiro) e para as possibilidades de ação da dança.

Anthony Giddens, no seu trabalho As Conseqüências da Modernidade, reafirma o conceito de lugar como "[...] cenário físico da atividade social [...]" (GIDDENS, 1991, p. 26-7), mas acrescenta a separação do espaço e do tempo, fator que estimula o surgimento de relações "[...] entre outros ausentes, localmente distantes de qualquer situação dada ou interação face a face [...]" (GIDDENS, 1991, p. 27), tornando o lugar cada vez mais fantasmagórico. As relações sociais são retiradas dos contextos locais e reordenadas a partir de grandes distâncias tempo-espaciais, através do que Giddens chama de "mecanismos de desencaixe" (GIDDENS, 1991, p. 29 e 59).

Podemos dizer que os espaços periféricos das cidades brasileiras carregam esses "desencaixes" e contrapontos a partir da "cidade central", que se organiza oferecendo oportunidades de emprego, de produção cultural, outras formas de consumo e hábitos, que integram o tempo vivido dos habitantes. Também são fantasmagóricos, pois são anunciados na mídia global, com imagens e notícias sobre violência e miséria, conectados com o mundo a partir de um aspecto de negatividade.

Nesse sentido, ENCARNADO possibilitou um contraponto interessante e positivo para aquele local e para todas as pessoas que assistiram ao espetáculo em outros lugares, com realidades muito distantes da brasileira, e que, de alguma maneira, já é problematizada constantemente pela própria Lia Rodrigues: mudar a residência artística de um trabalho de dança contemporânea para uma favela pode transformar a criação artística? Como a própria coreógrafa responde:

Isso é uma espécie de uma armadilha, porque isso é uma coisa também que as pessoas adoram; têm um fetiche muito grande coisa da favela.... Não só no exterior, mas no Brasil também (RODRIGUES apud GUZZO, 2008). 
Quando se pensa nas possíveis ações sociais da dança, verifica-se o seu reconhecimento como atividade desde as sociedades primitivas, que já relacionava questões sobre o espaço, o tempo e os mitos das comunidades, bem antes da sua estruturação em campo sistematizado do conhecimento e do espetáculo. A estrutura de dança que conhecemos hoje como "categoria cultural" emerge principalmente a partir do século XVII, com o surgimento do balé clássico.

Até a virada do século XIX para o século XX, o termo balé estava diretamente associado à dança espetacular, vista como uma das únicas possibilidades de se ver e apreciar o corpo dançante - sem falar, é claro, sobre as danças tradicionais ou camponesas de cada país e região que eram apresentadas de maneira "livre" nas ruas e nas festas populares. Uma nova construção de sentidos e significados foi realizada a partir do que se pode chamar de "projeto de elitização da dança", que passa a ser concebida como um divertimento da aristocracia cortesã (MONTEIRO, 1998).

O balé, como conceito, abrange elementos muito diferentes, que variam desde um balleto dançado por Guglielmo Ebreu na Itália, no Quattrocentro, a uma obra como La Sylphide, interpretada por Maria Taglioni no século XIX, até chegar a uma peça criada pelo American Ballet Theatre para um público dos dias atuais. Além disso, segundo Mariana Monteiro (1998), o balé foi uma invenção do Renascimento Italiano, conforme documentos datados do século XV. Anos mais tarde foi levado à França e de lá se espalhou pelo mundo ocidental durante os séculos XVII e XVIII.

É na Itália que se inicia a formação de uma sociedade cortesã, ainda não enrijecida pela etiqueta. Com a dança da corte, emerge uma nova etapa para a apreciação: ela se torna erudita com passos e métricas específicas. O próprio termo "balé" refere-se a uma circulação de discursos e repertórios sobre a dança da época. Segundo Monteiro (1998), o termo encontra-se relacionado à Balletti, que seria o diminutivo de Ballo, utilizado na Itália renascentista para designar "[...] danças executadas num salão de baile por uma elite cortesã" (MONTEIRO, 1998, p. 170).

As transformações da dança estão relacionadas aos movimentos políticos da monarquia e da elite burguesa. Ao profissionalizar-se entre os séculos XVI e XVII, essa arte afastou-se dos sentidos que possuía inicialmente para a população, de maneira geral. Essa profissionalização fez surgir novos papéis, tais quais: os mestres de dança, os bailarinos profissionais, as regras e a consequente elevação do nível técnico. Nos séculos 
seguintes, houve um grande aprimoramento técnico. A técnica do balé clássico, influenciada pela arquitetura renascentista, passou a se basear no virtuosismo dos passos, na harmonia e na leveza dos corpos desenhados nas coreografias.

No século XVII, sob a influência de Luís XIV, a dança da corte tornou-se a dança real. Conhecido como Rei Sol, desde muito jovem, tomou aulas de balé, dançou em muitos espetáculos e criou a figura do primeiro bailarino, perpetuando no palco a estratificação social da época, traduzindo a noção de frontalidade para os corpos que dançam. Luís XIV criou a Academia Real de Dança, que passou a formar bailarinos profissionais, de maneira a propiciar o desenvolvimento de novas investigações e aprimoramentos na dança, possibilitando, assim, o ingresso dessa arte no Século das Luzes, também com uma discursividade "iluminada". A criação de uma escola possibilitou que a profissionalização e a relação de mestre e discípulos fossem estabelecidas. Segundo Pereira (1998), nesse momento, a dança trazia a ideia dos divertissements ${ }^{8}$, com grandes dificuldades técnicas que agradavam ao público, ao demonstrar as possibilidades e as incríveis façanhas do corpo dançante.

O olhar histórico possibilita entender a influência do balé na forma de apresentação e de comunicação da dança como uma arte espetacular, que se perpetua até hoje na dança contemporânea. Muita coisa mudou, rupturas importantes a partir de artistas modernos permitiram à dança outras formas e formatos (FOSTER, 1986), mas algumas organizações permanecem: os grandes teatros, os salões, uma pequena elite apreciadora. Foi perpetuado e cristalizado um modelo político e estético que se sustenta ainda em muitos lugares.

No Brasil, por exemplo, a dança como conhecimento sistematizado, chega através do balé e desenvolve-se como um conhecimento também da elite. Para a maioria da população, a dança a que se tinha acesso era a popular, especialmente ligada à imagem do carnaval. A preocupação com uma dança engajada começa a surgir a partir dos anos 1970 com trabalhos tais quais os do Ballet Stagium ou as iniciativas de instituições que usavam a dança no processo de educação de jovens considerados carentes.

Muitos projetos artísticos de cunho social trabalham com a estetização da pobreza. A estetização da pobreza vê na favela brasileira uma mercadoria cultural, a partir da industrialização das expressões urbanas e de estilos de vida vindos da pobreza. Este fenômeno ocorre também na cena da cultura mundial, como aconteceu com a cultura negra norte-americana. A cultura da pobreza brasileira ganha visibilidade sendo fonte de significado e de identificação para um mercado esvaziado de estilos de vida diferenciados para se espelhar e vender: o
8. Para Monteiro (1998) o divertissement cumpria, como arte cortesã, uma função social específica de entreter os nobres. Era feito por nobres, para os próprios nobres. 
samba do morro, o funk, o hip hop, são produtos com alta rentabilidade. A ideia do made in favela no Brasil tornou-se uma "[...] tecnologia capaz de produzir uma capitalização e desvio de forças hostis máximas (exclusão, fome, miséria) em um ato criador" (BENTES, 2003, p.13).

São forças também de identidade brasileira que trazem símbolos importantes para o país - como o malandro, a mulata e o futebol - que estão associados às camadas mais pobres (SOUZA \& BARBOSA, 2005). Trata-se de uma convergência importante entre política e estética que relaciona as práticas culturais da periferia aos fluxos globais, que possibilita até a mídia enxergar. Uma mudança decisiva que inclui expressões culturais urbanas e estilos de vida vindos da pobreza, passando pela realidade da cultura letrada, tornando-se uma cultura visual e midiática. Essa exposição é "vendida" como uma atitude política renovadora, fora das instituições tradicionais, representando uma forma rizomática e vitalizante para a produção criativa no país. Essa "novidade" serve de inspiração e de estímulo para criação em arte contemporânea.

\section{Políticas para lugares que dançam}

Além dos questionamentos e inquietações pessoais de artistas que, como Lia Rodrigues, procuram sentido em sua ação artística, o crescente aumento de trabalhos que unem a arte à ação social também é um reflexo de uma política pública. A política cultural instaurada pelo Ministério da Cultura, a partir de 2003, teve um direcionamento claro de liberação de verbas para projetos que tivessem alguma contrapartida social. Essa indicação trouxe uma insatisfação da classe artística que se posicionou contra a responsabilidade do artista em promover ações de caráter social, além do seu próprio trabalho artístico (LEÃO, 2003). O próprio Ministério da Cultura colocou-se frente a esse direcionamento social para a cultura e a produção artística, declarando que a ideia de contrapartida social é um equívoco e que a grande relevância social seria a ampliação, a preservação e a restauração de museus, da produção livre de cineastas e artistas, isto é, que ocorresse o ato cultural em si.

À medida que se transfere para a iniciativa privada a decisão do que será patrocinado, restringe-se o patrocínio a projetos culturais que sejam lucrativos, ou que tenham forte apelo social, trazendo uma imagem "boa" para a empresa. Por conta disso, muitos aspectos da produção cultural são afetados, tais como: a massificação da produção artística, deixando para o artista a responsabilidade de transformar ou "animar" culturalmente a comunidade; a isenção da responsabilidade constitucional do governo no processo de desen- 
volvimento cultural do país; o dirigismo estético, atuando e estabelecendo normas e padrões artísticos a serem seguidos pelos artistas interessados nesse patrocínio e a promoção do assistencialismo (ações imediatistas sem efeitos estruturais mais profundos) como padrão de ação social (LEÃO, 2004).

A proposta de Lia Rodrigues de mudar a companhia para a Maré indica um comprometimento com o lugar, que extrapola um determinado trabalho ou projeto. O compromisso passa a ser com as conexões e com a identidade que aquele lugar imprime na vida da coreógrafa, dos bailarinos e do trabalho. O lugar, suas histórias, seus acontecimentos passam a produzir sentidos para a dança. E, provavelmente, a dança passa a produzir sentido para o lugar, ao longo do tempo, contribuindo para diminuir o isolamento entre o mundo da favela e da produção de arte contemporânea. Eleva-se, assim, o pensamento de Milton Santos, que propõe o lugar como locus de uma possível resistência à atual globalização e ao processo de verticalização dos lugares. Essa resistência se daria por meio do fortalecimento das horizontalidades entre os lugares e da reconstrução de "[...] uma base de vida que amplie a coesão da sociedade civil, a serviço do interesse coletivo" (SANTOS, 1996, p. 228). O autor propõe o desenvolvimento de uma solidariedade ativa, geradora de "[...] ações políticas locais que se anteponham às tendências meramente verticalizantes" (SANTOS, 1996, p. 228-9). Nesse sentido, a ação de Lia Rodrigues, ao deslocar sua companhia, parece contribuir para o contraponto de fazer criação de arte contemporânea na favela. O compromisso passa a ser com as conexões e com as multiplicidades que aquele lugar imprime na vida da coreógrafa, dos bailarinos e do trabalho. O lugar, suas histórias, seus acontecimentos passam a produzir sentidos para a dança, misturando-se com ela e a partir dela. 


\section{REFERÊNCIAS}

BENTES, Ivana. Made in favelas. GLOB(A.L.) - Revista do Instituto de Estudos do Trabalho e da Sociedade. Rio de Janeiro, n. o, jan. 2003.

CEASM. Centro de Estudos e Ações Solidárias da Maré. Disponível em: <http://www.ceasm.org.br>. Acesso em: 13 jun. 2016.

FOSTER, Susan Leigh. Reading Dancing: Bodies and subjects in contemporary American Dance. Berkley: University of California Press, 1986.

GIDDENS, Anthony. As Conseqüências da Modernidade. São Paulo: Martins Fontes, 1991.

GUZZO, Marina Souza Lobo. Dança em ação: políticas de resistência no ENCARNADO de Lia Rodrigues. Tese (Doutorado em Psicologia Social) - Programa de Pós-Graduação em Psicologia Social da Pontifícia Universidade Católica de São Paulo, 2009.

INNES, Kirstin. Pain Pleasure and politics of the flesh. The List, Issue 581, 2007. Disponível em: <http://www.list.co.uk/ articles/writer:kirstin-innes/page:7>. Acesso em: 08 set. 2008. KATZ, Helena. A contundente Cia. Lia Rodrigues para francês ver. O Estado de São Paulo, Caderno 2, 16 fev. 2005. Disponível em: <http://www.helenakatz.pro.br>. Acesso em: 15 jun. 2008. . Encarnado tece no corpo a trama da violência urbana.

O Estado de São Paulo, Caderno 2, São Paulo, 08 nov. 2007. Disponível em: <http://www.helenakatz.pro.br/>. Acesso em: 15 jun. 2008.

LEÃO, Doralice Soares. O papel da mídia impressa no embate Marketing Cultural X Marketing Social. Dissertação (Mestrado em Comunicação e Semiótica) - Programa de Estudos Pós-Graduados em Comunicação e Semiótica da Pontifícia Universidade Católica de São Paulo, 2003.

Política Cultural no Brasil: apontamentos e história. In: NORA, Sigrid. (Org). Húmus 1. Caxias do Sul: Itaú Cultural, 2004.

LEI 8.313 de 1991. Disponível em: <www.cultura.gov.br>. Acesso em: 23 ago. 2008.

LEITE, A. O Lugar: Duas Acepções Geográficas. Anuário do Instituto de Geociências. Rio de Janeiro, Universidade Federal do Rio de Janeiro, v. 21, 1998.

LEITE, Márcia Pereira. Entre o individualismo e a solidariedade: dilemas da política e da cidadania no Rio de Janeiro. Revista Brasileira de Ciências Sociais, v. 15, n. 44, out., 2000. 
Disponível em:<http://www.scielo.br/pdf/rbcsoc/v15n44/4148. pdf $>$. Acesso em: 13 jun. 2016.

LIA RODRIGUES. Companhia de Danças. Disponível em: <http:// www.liarodrigues.com/index.html>. Acesso em: 13 jun. 2016.

MELLO, João Baptista Ferreira de. Geografia Humanística: a perspectiva da experiência vivida e uma crítica radical ao positivismo. Revista Brasileira de Geografia. Rio de Janeiro, IBGE, 52, n. 4, p. 91-115, 1990.

MONTEIRO, Marianna. Balé, tradição e ruptura. In: Lições de Dança, v. 1. Rio de Janeiro: UniverCidade, 1998.

REDES DA MARÉ. Disponível em: <http://www.redesdamare. org.br>. Acesso em: 13 jun. 2016.

RELPH, Edward. As bases fenomenológicas da geografia. Geografia. Rio Claro, Unesp, v. 4, n. 7, p. 1-25, abr., 1979.

RODRIGUES, Lia. Corpo em evidência. Revista E, n. 129, fev., 2008. Disponível em: <www.sescsp.org.br/sesc/revistas>. Acesso em: 15 jun. 2008.

SANTOS, Milton. A natureza do espaço: técnica e tempo, razão e emoção. São Paulo: Hucitec, 1996.

SILVA, Jailson de Souza \& BARBOSA, Jorge Luiz. Favela: alegria e dor na cidade. Rio de Janeiro: Brasil e SENAC, 2005.

SONTAG, Susan. Diante da dor dos outros. São Paulo: Cia. Das Letras, 2003.

TUAN, Yi-Fu. Place: an experiential perspective. Geographical Review, v. 65, n. 2, p. 151-165, 1975. Disponível em: <http:// links.jstor.org/sici?sici=0016-7428\%28197504\%2965\%3A2\%3C151\%3APAEP\%3E2.0.CO\%3B2-J>. Acesso em: 13 jun. 2016.

TUAN, Yi-Fu. Espaço e Lugar. São Paulo: Difel, 1983. 